\title{
Política de segurança dos EUA para a América Latina após o final da Guerra Fria
}

\author{
MONICA HERZ
}

\section{Introdução}

$\mathrm{O}$ S ANOS DE 1990 foram marcados por algumas mudanças significativas nas relações entre os Estados Unidos e a América Latina. A indefinição de uma política hemisférica clara se aliava à ênfase nos interesses econômicos, à afirmação do modelo neoliberal e à perspectiva de um multilateralismo limitado porém emergente (1). Depois de um período dominado pelas expressões da Segunda Guerra Fria no continente, as iniciativas da administração Bush concentraram-se em estreitar os laços econômicos entre os EUA e a América Latina, negociando o Acordo de Livre Comércio da América do Norte (Nafta) e lançando a Iniciativa para as Américas. A mudança teve caráter paradigmático, havendo um translado de uma política mais coerciva e ideológica para uma perspectiva que enfatizava a cooperação, maiores investimentos e comércio. As duas administrações seguintes, sob liderança de Bill Clinton, mantiveram objetivos similares. A partir de janeiro de 1994 passou a vigorar o Nafta, dando continuidade ao processo de integração das economias dos Estados Unidos, Canadá e México, além de alguns países da bacia do Caribe. A negociação do Tratado de Livre Comércio das Américas seria o passo seguinte.

A política externa americana no período foi redesenhada nos termos de um multilateralismo limitado às áreas e aos temas para a coordenação de políticas congruentes com os interesses norte-americanos. Contudo, a tensão entre iniciativas multilaterais e o unilateralismo na política externa norte-americana é mantida e, ainda em 1989, dá-se continuidade à tradição de intervenções militares de caráter unilateral na região, com a invasão do Panamá e a apresentação do presidente daquele país à Justiça norte-americana (2). A prática de certificar os países que colaboram no combate ao narcotráfico e as interferências nos processos políticos domésticos, como ocorreu recentemente na Venezuela, atestam para o privilégio dado a esta opção em determinadas circunstâncias. Ao mesmo tempo, abre-se um debate sobre o papel que os EUA deveriam preencher como liderança regional; está em questão a disposição do governo norte-americano de arcar com os custos dos mecanismos de normatização da ordem regional (3). 
Em termos de objetivos estratégicos, o governo norte-americano se concentraria em duas agendas: a promoção das reformas neoliberais e o combate ao comércio ilícito de drogas. A agenda de segurança deve ser compreendida neste contexto. Assim, neste trabalho salientarei as linhas mestras da política de segurança norte-americana na região, enfatizando a percepção de novas ameaças na forma da fragilidade das instituições democráticas, do trafego ilícito de drogas e da imigração ilegal. A presença militar norte- americana no continente também será focalizada, como expressão de elementos de ruptura e continuidade de sua política. Finalmente, concluirei salientando as contradições inerentes aos diferentes aspectos da política de segurança norte americana.

\section{Tendências gerais da política de segurança norte-americana no hemisfério}

A política de segurança de um país pode ser definida de formas variadas. Desde os anos de 80, uma vasta literatura vem redefinindo o conceito de segurança, tratado agora de forma menos objetivista e perdendo a lógica da estratégia de deterrência seu lugar central. Por outro lado, há um debate em curso sobre o escopo do conceito de segurança, tendo sido um conceito mais abrangente incorporado a bibliografia e a prática política (4). Neste trabalho, as tendências na construção do interesse nacional norte-americano vis-à-vis a América Latina serão investigadas, restringindo-se o texto aos temas que envolvem o uso ou a ameaça de uso da violência por parte do Estado. Assim, a definição de ameaças ao Estado e/ou à nação por parte dos governos americanos, seu aparato de Estado e as estratégias elaboradas são o foco da análise.

A definição de ameaças à segurança do Estado e da nação norte-americana ao final da década de 1990 incluía: a agressão a Estados, em particular, aqueles que adquirem armas de destruição em massa; ameaças transnacionais, como organizações terroristas e criminais; a difusão de tecnologias perigosas associadas às armas de destruição em massa; Estados falidos ou aqueles que "sucumbem" à disputas religiosas, culturais, raciais ou tribais; serviço de inteligência de outros países e o possível acesso a segredos diplomáticos, tecnológicos, econômicos ou comerciais americanos, e problemas ambientais e de saúde (5). A partir da definição dessas ameaças, a estratégia seria aumentar a segurança dos Estados Unidos e sua prosperidade econômica, além de promover a democracia e os direitos humanos.

Observa-se que a América Latina não constitui uma região de alta prioridade por uma série de motivos. Destaca-se a necessidade de estabelecer uma hierarquia de prioridades para distribuição de recursos e atenção. As regiões diretamente afetadas pela desestruturação do império soviético, a busca de controle sobre as regiões petrolíferas no Oriente Médio e aquelas próximas ao Mar Cáspio, o conflito árabe-israelense, as ameaças advindas da proliferação de armas de destruição em massa em um conjunto de países, a necessidade de reestruturar 
a aliança atlântica e, finalmente, o terrorismo transnacional, não deixavam lugar para um olhar mais atento sobre o nosso hemisfério.

A proliferação de armas de destruição em massa é percebido como uma das principais ameaças à segurança dos EUA, e o hemisfério parece estar caminhando de encontro à visão de ordem internacional privilegiada pela elite decisória norteamericana. Os projetos de aquisição de armas nucleares foram abandonados e acordos e declarações afirmam que a região está livre das armas de destruição em massa (6). Apesar das tensões que envolvem o governo de Hugo Chaves na Venezuela, $\mathrm{o}$ acesso às importações de petróleo não foram apresentadas como uma ameaça ao longo da década. Finalmente, a transição para a democracia formal em todos os países do continente, com exceção de Cuba, tranqüiliza as lideranças em Washington.

Contudo, partindo da definição de ameaças acima, observa-se ainda uma tendência à expansão da agenda de segurança norte-americana no hemisfério, que passou a incluir o apoio à democracia, política de migração, proteção de fronteiras, terrorismo, tráfico de drogas, desastres naturais e meio ambiente; além dos temas mais tradicionais, como o controle de produção e transferência de armamentos, resolução de disputas de fronteira, o papel das organizações regionais ou globais de segurança e as insurreições armadas. Destacam-se dentre esses o tráfico de drogas e a imigração ilegal que são objetos de políticas envolvendo o uso ou a ameaça do uso de violência.

As ameaças identificadas geram uma modificação significativa na definição da relevância de diferentes sub-regiões. A região andina adquire maior importância para a alocação de recursos no contexto do planejamento estratégico do Estado norte-americano, em contraposição à relevância da América Central durante os anos 80. A produção de drogas nesta parte do hemisfério, a preocupação com os "Estados falidos" e a necessidade de diversificar a presença norte-americana com o fechamento da base militar no Panamá, planejada para o final de 1999, explicam esta mudança. Como resultado da maior relevância que a região andina adquire no contexto dos objetivos estratégicos norte-americanos houve uma extensão da zona de influência imediata. A distribuição de bases, os acordos militares assinados, a assistência concedida a esses países atestam para esta mudança.

A guerra na Colômbia passa a ser um dos pontos focais da política de segurança norte-americana no hemisfério. Este conflito envolve um conjunto de elementos já identificados como ameaças aos EUA: a criminalidade transnacional, especificamente o tráfico de drogas e de armas, a perda de controle do Estado sobre o território e a conseqüente ausência de implementação da lei, além da presença de grupos insurgentes de esquerda. Além de prover $80 \%$ da cocaína que chega aos Estados Unidos e uma proporção cada vez maior da heroína consumida naquele país, a Colômbia representa um grande interesse geopolítico em termos de comércio, origem de migrantes e efeito do conflito sobre a segurança da região andina. 
A Administração Clinton buscou estabelecer uma divisão entre o apoio militar e econômico para a erradicação da produção e comércio de drogas ilícitas e o apoio à contra insurgência, ainda como resultado da chamada "síndrome do Vietnã". A política do Governo Bush após 11 de setembro e o fim das negociações de paz entre o governo colombiano e a guerrilha em fevereiro de 2002 abrem as portas para um aumento da assistência militar norte-americana à Colômbia, e o apoio à contra-insurgência volta à agenda política. A ajuda ao controle do território por parte do Estado colombiano através de assistência, sem o envio de tropas, passa a receber atenção central da política americana (7). A percepção em Washington de que um Estado fraco, que não controla seu território e tem baixa legitimidade é uma ameaça à segurança regional, e foi potencializada pelos ataques de 11 de setembro e a "guerra antiterror" construída a seguir.

As instituições criadas no contexto da Guerra Fria serão revistas a partir de novas percepções de ameaças. Abre-se um debate sobre o papel dessas instituições, que haviam servido para conter o comunismo desde a Segunda Grande Guerra. Durante o Governo Bush (pai), a postura coercitiva da administração anterior perdeu seu status central na elaboração da política externa americana e uma nova ênfase na cooperação multilateral pôde ser observada. Neste contexto, novas formas de associação regional foram estimuladas.

A criação de novos mecanismos ad hoc de concerto, além das mudanças realizadas no âmbito da OEA nos últimos dez anos, refletem esta perspectiva. Os mecanismos de cooperação multilateral, como a Cúpula das Américas, a OEA, a Junta de Defesa Inter-Americana, as Reuniões de Ministros da Defesa das Américas serão fóruns privilegiados pelas três primeiras administrações do pós-Guerra Fria. Observa-se uma tentativa de fornecer um novo sentido ao sistema de segurança hemisférico. Como indica Jorge Domingues, embora tendências ao multilateralismo e ao unilateralismo coexistam, identifica-se uma disposição para o fortalecimento do multilateralismo regional (8).

Em 1994, teve início a Reunião de Cúpula das Américas. Em 1995, o Departamento de Defesa dos Estados Unidos organizou a $\mathrm{l}^{\text {a }}$ Conferência de Ministros da Defesa do Hemisfério em Williamsburg, Virginia. A revisão do papel da OEA no campo da segurança, com a criação do comitê de segurança em 1995, e da Comissão Inter-Americana para o Controle do Abuso de Drogas (Cicad) (9), é incentivado pelos EUA. A invasão do Haiti em 1994 foi o primeiro caso em que o governo norte-americano buscou a aprovação multilateral para o uso de força militar no continente. Os governos também estimularam o debate sobre a redefinição do papel da Junta Inter-Americana de Defesa, para que ela pudesse assumir uma posição mais clara na administração da segurança regional (10). A Junta foi criada em 1942, e é um órgão de aconselhamento da OEA, financiada por ela mas não subordinada a ela politicamente. A Junta hoje dedica-se aos projetos de desminamento, à catalogação de medidas de confiança mútua, à ajuda em casos de desastre e às atividades específicas do Colégio Inter-Americano de Defesa. 
Os temas das conferências dos ministros de Defesa expressam a nova visão de cooperação hemisférica no campo da segurança. A criação de medidas de confiança mútua, a cooperação no campo da defesa e o novo papel dos militares foram discutidos. A ênfase sobre a cooperação multilateral pode ser observada nos esforços para o envolvimento da OEA na crise haitiana e dos quatro países garantes do tratado do Rio de Janeiro nas negociações de paz entre Peru e Equador (11).

O paradigma da segurança cooperativa passa a ser um dos pilares da política de segurança dos EUA para o continente. O conceito e a prática de medidas de confiança mútua foram incorporados às doutrinas de segurança nos diferentes países latino-americanos (12). A troca de informação, com o aumento da transparência e a redução da percepção de ameaças, a criação de canais de comunicação, o acesso às atividades militares de outros países, o aumento da previsibilidade através da notificação quanto às atividades militares e a criação de restrições às atividades militares são os pressupostos desta agenda. A participação dos militares em missões de paz multilaterais é vista como parte deste translado, que modificaria o papel e a perspetiva das Forças Armadas latino-americanas (13).

A expansão da agenda de segurança e a diversificação de estratégias e práticas neste campo deve ser entendida a partir da idéia de que a incerteza do mundo pós-Guerra Fria é como um guarda-chuva de todas as ameaças (14). O choque dos aviões comerciais contra as torres do World Trade Center parecia confirmar que este é um mundo imprevisível e repleto de ameaças. Especificamente no que se refere à América, já no início da década verifica-se a identificação da instabilidade regional e do vácuo de poder gerado pelo final da Guerra Fria como principais ameaças à segurança norte-americana (15).

A estratégia militar visa a responder a esta perspectiva. Nos documentos do período, as operações permanentes ou temporárias de tropas americanas fora do território daquele país (o termo utilizado é forward presence operations) são enfatizadas. O impacto para a constituição de uma estratégia para o hemisfério ocidental é mais evidente na disposição temporária de tropas, na busca de cooperação na área militar, gerando maior previsibilidade nas relações militares e na defesa da democracia (16).

A preocupação com a instabilidade regional no contexto do final da Guerra Fria está fortemente associada à ênfase dada pelas sucessivas administrações norte-americanas à não-proliferação de armas de destruição em massa. Essa preocupação se estende na disseminação das capacidades militares convencionais avançadas. Desde o início da década de 1990, a pressão para que os países latinoamericanos, que ainda não haviam assinado os tratados de não-proliferação, $\mathrm{O}$ fizessem foi exercida de forma sistemática. A existência de uma diversidade de materiais com uso duplo - militar e civil - dificulta as negociações neste campo. No entanto, os avanços foram significativos do ponto de vista norte-americano, tendo a Argentina e o Brasil se acomodado aos regimes de não-proliferação. 
A diferença entre a definição de ameaças por parte dos governos norteamericanos e o processo de construção de interesses que ocorre no âmbito de cada um dos países latino-americanos gera um conflito potencial na região, enquadrado na enorme assimetria de poder que tradicionalmente a carateriza. As relações entre os Estados Unidos e os países da América Latina na esfera militar tornam-se foco de uma revisão e um intenso debate que pode ser observado nas publicações das diferentes Forças Armadas no continente. O final da Guerra Fria, como lembra AugustoVaras (17), teve um impacto sobre a política de segurança norte-americana muito mais dramático do aquele que se observou ao sul do Rio Grande.

A política de revisão do papel das Forças Armadas na América Latina implementada pelos Governos Bush e Clinton não encontra a esperada ressonância na região, que viria a enfrentar um conflito armado em 1995 entre o Peru e o Equador, ainda tinha um conjunto de disputas fronteiriças (18) a resolver e buscava acompanhar, ainda que tardiamente, o desenvolvimento tecnológico no campo militar, além do complexo processo de redefinição do papel dos militares em cada um desses países, o qual gera uma tendência à exacerbação da defesa de interesses corporativos. Ademais, setores das elites latino-americanas percebem um aumento de ameaça à soberania estatal como resultado do próprio processo de integração econômica, da redefinição de "ameaças à paz internacional” no âmbito das Nações Unidas, passando a incluir o desrespeito aos direitos humanos e crises humanitárias, além da contínua política unilateralista norte-americana.

$\mathrm{Na}$ verdade, o período de maior alinhamento entre os interesses dos EUA e os demais países do continente no campo da segurança ocorreu após a Segunda Guerra. Até os anos de 1960, bens coletivos como investimentos, segurança, armas e ideologia foram gerados pelos norte-americanos, além da construção de instituições em um exercício de liderança hegemônica. Augusto Varas (19) salienta que o período de maior aproximação na definição de ameaças e estratégias foi extremamente curto.

Em contraposição, durante o Governo Reagan, a "Segunda Guerra Fria" adquiriu contornos particulares no hemisfério com a rollback policy implementada em Granada, na Nicarágua e no Panamá (20). A política coercitiva e ideológica do período gerou um dos mais significativos movimentos de concertação exclusivamente latino-americano: o grupo de Contadora e seu grupo de apoio. A visão de interesses de segurança compartilhados foi ainda fortemente atingida pelo papel exercido pelos Estados Unidos durante a Guerra das Malvinas e pelas invasões unilaterais de Granada e do Panamá.

Por outro lado, existem divergências importantes quanto ao regime de não- proliferação de armas. Entre os militares a exclusão de países latino-americanos de programas de assistência, como decorrência da política de direitos humanos de Jimmy Carter (21) e dos requerimentos dos regimes de não-prolifera- 
ção nuclear, tiveram efeitos importantes, ressaltando a tendência desta parcela do aparato de Estado de assumir uma posição defensiva em relação ao princípio da soberania.

A natureza das ameaças supracitadas dificulta a divisão entre esferas civis e militares, entre o interno e o externo, sendo difícil de definir as jurisdições de diferentes agentes não são claras. O incentivo para que as Forças Armadas latinoamericanas participem de operações policiais no contexto da luta antidrogas ou se concentrem na preparação para operações de paz entra em conflito com a auto-imagem das diferentes corporações como defensoras da integridade territorial do Estado.

A política de transferência de armas foi revertida pela Administração Clinton por meio da diretiva presidencial $n^{\circ} 34$, que apresenta a transferência de armas convencionais como um instrumento legítimo da política externa norte-americana. Desta feita, uma moratória de 20 anos para a venda de armas de tecnologia avançada foi suspensa a partir de 1997. A venda de caças F-16 para o Chile representou uma guinada tecnológica em relação às armas comercializadas pelos Estados Unidos na região. O principal incentivo para esta mudança foi econômico, tendo a indústria bélica americana pressionado o governo para mudar uma política que reservava o mercado latino-americano a empresas européias e israelenses. Contudo, uma maior participação norte-americana no processo de modernização das forças aéreas latino-americanas favorece a busca de maior influência nesta área.

Algumas mudanças anteriores podem ser observadas. Em fevereiro de 1993, um memorando de entendimento entre os Estados Unidos e a Argentina permitia a compra de equipamento de informática avançado, e tecnologia nuclear e química e sistemas de guia aeronáuticos. A Argentina concordou em estabelecer mecanismos de controle para suas exportações de tecnologia militar (22). A política do Governo Reagan de vender armas avançadas a países aliados permitiu uma maior abertura de comércio de armas no continente; no entanto, a única venda de caças avançados foi feita em 1982, para a Venezuela, com o objetivo de contrabalançar a aquisição de MIG-23 soviéticos pelos cubanos. O embargo à venda de armas para o Chile foi suspenso e a venda de aviões A-4M Skyhawk para a Argentina foi aprovada, quebrando uma política instituída ainda durante o conflito no Atlântico Sul.

Finalmente, cabe ressaltar que, durante os anos de 1990, o governo norte-americano deu continuidade à sua política anticubana, produzindo um conjunto de legislações que visavam a isolar o país do sistema internacional. A contínua marginalização de Cuba dos arranjos de segurança regionais é outra característica da política de segurança norte-americana para o hemisfério que deve ser ressaltada. Esse país não é considerado no contexto da agenda de segurança cooperativa, e consta de uma lista de sete países (Irã, Iraque, Coréia do Norte, Sudão e Síria) que não podem receber assistência na área de segurança (23). 


\section{Segurança e o paradigma democrático}

O funcionamento da democracia e das economias de mercado no hemisfério ocidental constitui um dos objetivos centrais da política externa norte-americana para a região. Como vimos, o fortalecimento da democracia é uma das estratégias de segurança do Estado americano.

Ainda durante a presidência de Jimmy Carter, este tornou-se um objetivo da política externa norte-americana, tendo sido posteriormente endossado pela segunda administração Reagan. Os processos de democratização e pacificação que caracterizaram a maior parte da região durante os anos 80 permitiram às elites decisórias nos Estados Unidos chegar ao entendimento de que se constituíra uma sólida fundação para a construção de suas políticas. Dentre as justificativas para o uso da força no Panamá e no Haiti, a defesa das instituições democráticas é mencionada. Por outro lado, recursos diplomáticos significativos foram usados para fortalecer as instituições democráticas no Peru, na Guatemala e no Paraguai.

A Cúpula das Américas, realizada em dezembro de 1994, em Miami, ratificou o consenso regional em relação à superioridade do regime democrático liberal. O Plano de Ação gerado no encontro claramente vincula democracia à estabilidade regional. A associação entre a promoção da democracia e a segurança emerge da percepção de que ño instituições demoṎ̈́áticas em muitos dos países da região são frágeis e que a estabilidade adquirida está sob constante ameaça. Por outro lado, o combate a outras ameaças mais evidentes, como as drogas e a migração ilegal, poderia ser prejudicado caso o paradigma democrático não se consolidasse (24).

Dessa forma, recriava-se sob novo prisma a tradicional imagem da América Latina e de suas elites, cuja capacidade de criar instituições de governância estáveis e democráticas é questionada. A natureza tutelar da política externa norteamericana para a América Latina cristaliza-se nos anos de 1990 em um projeto de fortalecimento das instituições da democracia liberal.

Dentre as esferas de cooperação que o governo americano buscou incentivar no período destacam-se a proteção e a consolidação da democracia, correspondendo a uma orientação mais geral da política externa americana em que a criação e consolidação de regimes liberais democráticos adquirem centralidade. Neste sentido, agências como o National Endowment for Democracy (NED) e programas como o Democratic Initiatives Program da Agencia International de Desenvolvimento dos Estados Unidos (AID) e instituições regionais criadas no âmbito da OEA, com incentivo norte-americano, serão instrumentais. A Resolução $\mathrm{n}^{\circ} 1.080$ da Assembléia Geral da OEA, em 1991, daria início, ao processo de criação de um aparato institucional de proteção à democracia. A Resolução, ou Declaração de Santiago, foi aplicada para condenar o golpe de 1991 no Haiti, no Peru em 1992, na Guatemala em 1993 e no Paraguai em 1996. A reu- 
nião de Cúpula de 1994 havia gerado o incentivo para o fortalecimento das instituições multilaterais de proteção à democracia no hemisfério. Em 1997, uma reforma da carta da OEA ratificou o protocolo de Washington de 1992. A nova carta dá à Organização o direito de suspender um membro quando ocorre quebra institucional. Finalmente, em 2001 a Carta Democrática Inter-Americana é adotada. A criação da Unidade para a Promoção da Democracia, uma agência da OEA que visa a assistir o fortalecimento de instituições democráticas, também contribuiu para a consolidação do paradigma democrático na região.

A mudança da política norte-americana em face da tradição de autonomia dos militares nas sociedades latino-americanas já pode ser observada no final dos anos de 1980. Até mesmo o currículo das instituições para treinamento de oficiais latino-americanos foi modificado, tendo sido incluídos temas como instituições democráticas e respeito aos direitos humanos. O governo norte-americano incentivou a formação de ministérios de defesa, em contraposição a ministérios específicos para cada uma das Forças Armadas, no contexto de um discurso mais amplo que enfatiza a consolidação democrática e o pressuposto do controle civil sobre as instituições castrenses. No âmbito doméstico, o debate sobre direitos humanos continua, e é criada a legislação que proíbe ajuda militar a unidades que violem os direitos humanos com impunidade (Lei Leahy, 1997).

\section{Drogas e migração ilegal}

Enquanto a lógica da política de segurança norte-americana para o hemisfério calcava-se sobre a ameaça advinda de potências externas, pelo menos até o final da Guerra Fria, hoje auelas que surgem no próprio continente americano adquirem crescente relevância. As "novas ameaças" que galvanizam energias em Washington são as migrações descontroladas e o tráfico de drogas. Em 1999, os principais problemas para a segurança eram descritos da seguinte forma: "The principal security concerns in the hemisphere are transnational in nature, such as drug trafficing, organized crime, money laundering, illegal immigration, firearms trafficking, and terrorism" (25).

No início da Administração Bush, foi declarada uma "guerra contra as drogas", e uma estratégia nacional de controle de drogas foi elaborada. Os recursos do fundo antidrogas foram aumentados de $\$ 4,3$ bilhões para $\$ 10,6$ bilhões entre 1989 e 1991, sendo que 70\% deste montante destinava-se a lidar com o suprimento de drogas. A mesma administração organizou duas reuniões de cúpula para lidar com o assunto: em Cartagena, em fevereiro de 1990 e em San Antonio, Texas, em fevereiro de 1992 (26). Em um testemunho diante do Congresso norte-americano em 1992, o comandante do Comando Sul, General George A. Joulwan, afirmou que a luta antidrogas era a sua prioridade número l (27).

Contudo, a definição do tráfico de drogas como uma ameaça aos Estados Unidos já vinha sendo construída há décadas. Ainda em 1971 o presidente Richard 
Nixon havia declarado o tráfico de drogas como uma ameaça à segurança nacional. Nos anos 80, o Governo Reagan expandiu os esforços de combate às drogas a partir da teoria de narcoguerrilha, elaborando-se uma associação entre os cartéis de drogas colombianos, as guerrilhas esquerdistas e Cuba. Em 1986, é estabelecido um mecanismo de certificação unilateral, que estabelece que o presidente dos EUA deve relatar ao Congresso quanto à cooperação de cada país no combate às drogas. O país "sem certificação" não pode receber crédito do governo americano e um voto negativo norte-americano pode ser emitido em instituições financeiras multilaterais; além disso, sanções comerciais são previstas. Ao final de 1993, o Governo Clinton buscou desmontar a conexão entre o cultivo de cocaína e a produção da pasta de coca no Peru e na Bolívia, e as refinarias e os distribuidores na Colômbia (28). A transferência do cultivo para a Colômbia ocorreu como resultado dos sucessos obtidos no Peru e no Equador.

Em 1998, o Congresso norte-americano aprovou o "Western Hemisphere Drug Elimination Act", permitindo um aumento significativo do financiamento às operações antidrogas no continente. A agência dentro do departamento de Estado responsável pela gestão da guerra contra as drogas (Bureau for International Narcotics and Law Enforcement Affairs-INL) poderia assim intensificar suas atividades, que incluem esforços de substituição de cultivos, fumigação, reformas judiciais, transferência de armas e treinamento de militares e forças policiais.

Em 2000, um pacote de $\$ 1,3$ bilhões de ajuda à Colômbia foi aprovado. Um dos principais componentes do "Plano Colômbia", elaborado inicialmente pelo governo colombiano, é a assistência norte-americana para o combate às drogas, tendo esta agenda dominado as relações bilaterais nos últimos anos. $\mathrm{O}$ plano previa o gasto de $\$ 7,5$ bilhões (recursos externos e internos) para enfrentar a crise colombiana. A premissa é de que os recursos do tráfico devam ser eliminados para que as guerrilhas e os grupos paramilitares não tenham acesso aos meios necessários para dar continuidade à guerra civil naquele país. A política de George Bush, criando a "iniciativa andina”, representa assim uma expansão destes esforços. O plano de cinco anos contava com \$2,2 bilhões para o combate ao tráfico de cocaína na Colômbia, Peru e Bolívia.

Como conseqüência da ênfase dada ao controle do suprimento de drogas observa-se uma tendência à crescente militarização dos esforços antidrogas do governo norte-americano, embora suas tropas não se envolvam direitamente com produtores ou contrabandistas de drogas. Em 1989, o Departamento de Defesa tornou-se a agência que lideraria a interdição de drogas no exterior. Em 1991, uma legislação específica autorizou o Pentágono a usar seus fundos para treinar militares e forças policiais, assim como transferir equipamento no contexto da guerra antidrogas (29). As relações entre militares latino-americanos e norteamericanos foram intensificadas como resultado do combate ao narcotráfico, tendo o governo dos EUA preferencia pelo uso de forças militares e não policiais neste 
contexto (30). A partir de 1999, as forças policiais deixam de ser os maiores receptores de assistência norte-americana (31).

O tratamento da migração como uma questão de segurança faz parte do movimento de expansão do conceito de segurança por parte de políticas de Estado e de governo, assim como pela literatura acadêmica sobre o assunto. Os imigrantes podem tornar-se uma ameaça por desestabilizarem as relações bilaterais, se oporem ao regime do país que os recebe, violarem as normas da cultura local e determinado grau de homogeneidade de uma comunidade ou representarem um custo financeiro (32). Nos anos de 1990, observa-se uma mudança de atitude em relação à imigração nos EUA, alimentada pela recessão econômica e pelo final da Guerra Fria, que colocava em dúvida o envolvimento internacional dos Estados Unidos.

No caso específico da América Latina, a imigração da América Central e o fluxo de migrantes cruzando ilegalmente a fronteira com o México recebem particular atenção por parte das autoridades. Durante os anos de 1980, os conflitos na América Central geraram grandes deslocamentos populacionais; assim, ondas de migrantes de El Salvador, da Guatemala e da Nicarágua chegaram aos EUA.

A migração advinda do Haiti e de Cuba, em particular, foi percebida como ameaça durante o período. Depois do golpe contra o presidente Aristide, o número de haitianos interditados pela guarda costeira norte-americana aumentou substancialmente. O governo americano chegou a levar 20 mil haitianos para a base de Guantanamo até a intervenção no Haiti em setembro de 1994. O problema gerado pelo fluxo de migrantes haitianos foi uma variável relevante para que se tomasse a decisão de intervir militarmente naquele país e tornou-se um tema importante da campanha eleitoral que levaria Clinton à Casa Branca. $\mathrm{O}$ estabelecimento de um governo constitucional no Haiti permitia aos Estados Unidos recusar aos haitianos o status de refugiados ou exilados.

Entre 1959 e 1993, mais de 600 mil cubanos tornaram-se residentes permanentes nos Estados Unidos, tendo como base legal os termos do Cuban Adjustment Act. No entanto, a partir de 1994, houve uma mudança na política americana como resultado da confluência dos fluxos migratórios cubanos e haitianos, de mudanças nas posições defendidas pela comunidade cubano-americana e do aumento de migrantes durante os anos de 1990. Migrantes cubanos também foram levados para Guantanamo e um acordo entre o governo norteamericano e o cubano favoreceu a volta de cubanos ao seu país e a reimposição de restrições à partida de migrantes pelo governo cubano (33). Desta forma, a base militar de Guantanamo torno-se um "lugar seguro" que limitava o acesso às costas norte-americanas. Por outro lado, a preocupação com a imigração ilegal da América Central contribuiu para a militarização da fronteira entre os EUA e o México. 
$\mathrm{Na}$ mesma linha adotada para lidar com outras questões de segurança hemisférica, o Governo Clinton buscou estabelecer mecanismos multilaterais de cooperação nesta área. Em 1996, o Processo de Puebla foi iniciado como uma conferência regional sobre migração realizada em Puebla, México. Os países centro-americanos e o Canadá, além dos Estados Unidos e do México participaram deste esforço. No segundo encontro sobre migração realizado em março de 1997, no Panamá, as partes concordaram em criar um grupo de consulta regional sobre migração e adotaram um plano de ação (34).

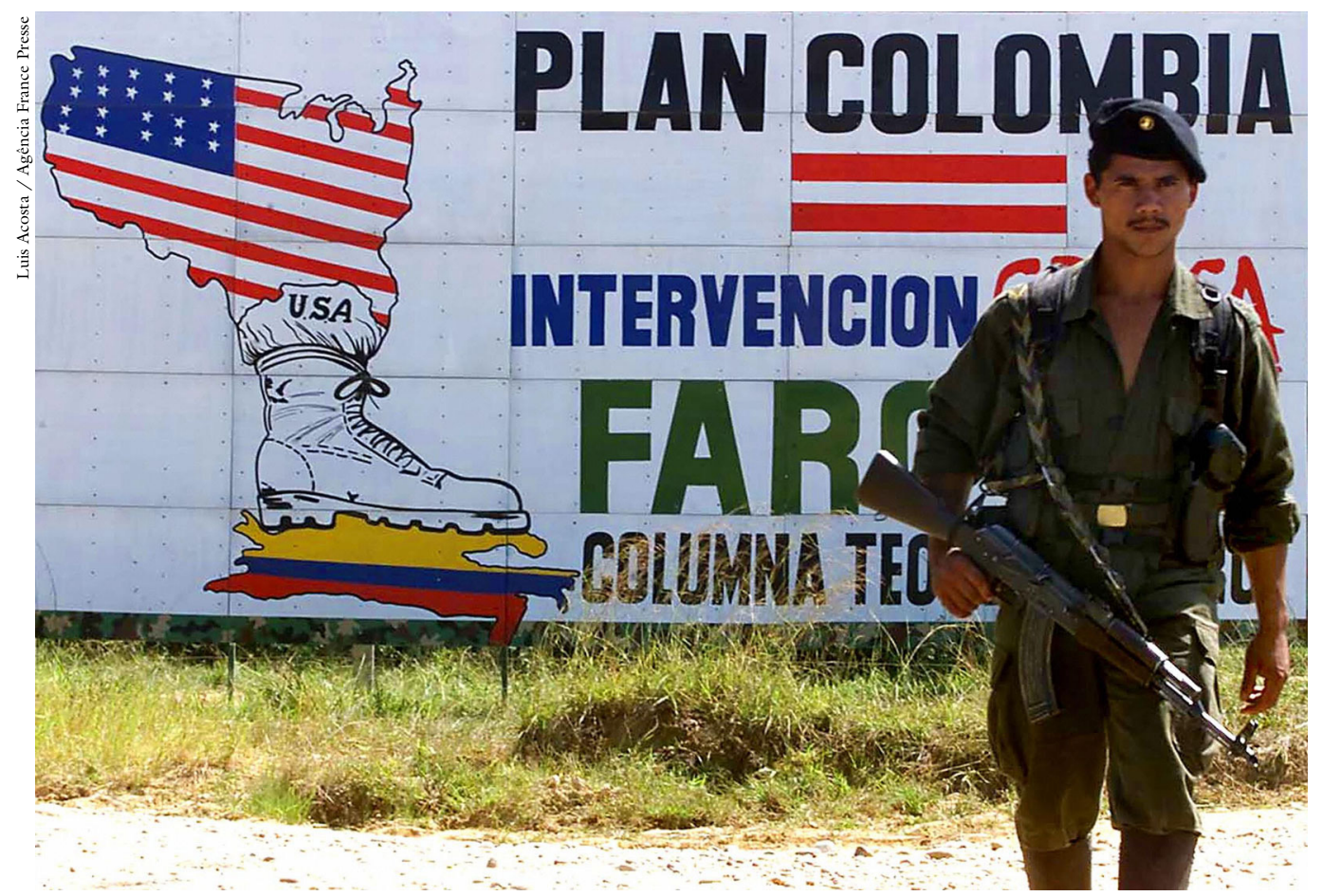

Guerrilheiro vigia estrada próximo de um cartaz de propaganda contra o Plan Colômbia

\section{Assistência militar e presença militar}

A experiência de intervenções militares no hemisfério ocidental favorece a visão de que esta é uma opção a ser considerada pelas elites decisórias norteamericanas (35). Embora a intervenção no Panamá tenha sido a última intervenção militar unilateral dos EUA, o uso da força, para realizar objetivos considerados essenciais, volta à pauta com o processo de elevação do comércio e produção ilícitos de drogas ao status de ameaça à segurança nacional.

Na verdade, os anos de 1990 são marcados por uma crescente militarização da política de segurança norte-americana no hemisfério, observando-se uma maior participação dos militares na constituição de uma estratégia para a região (36). A baixa relevância da região, particularmente depois dos atentados de 11 de setembro, facilita esse processo, estando os recursos do Departamento de Estado vol- 
tados para as regiões de maior relevância política. Neste contexto, é mais fácil aumentar o orçamento de defesa. O carro-chefe deste processo é a guerra contra o narcotráfico.

O Comando Sul das forças militares norte-americanas (Southcom) é o mais importante ator militar na região, responsável por uma complexa rede de funções e instalações. Estão sob sua responsabilidade ações em 19 países, ou seja, todos os países da América Latina excluindo-se o México e a Guiana Francesa. Em 1997, sua sede de operações foi transferida para Miami. As operações antidrogas e o contato com os militares da região são seus principais objetivos (37).

Desde a Segunda Guerra, diversos programas foram criados pelo governo norte-americano com o objetivo de fortalecer as instituições militares no hemisfério e aumentar a influência dos EUA. A ajuda militar direta, os programas de treinamento e a venda de armas compõem esses programas. Observa-se um declínio destas atividades nos anos de 1980, como demonstram os dados do Departamento de Defesa dos Estados Unidos. O aumento específico depois da revolução nicaraguense foi designado para a América Central e para os países andinos no contexto da luta antidrogas (38).

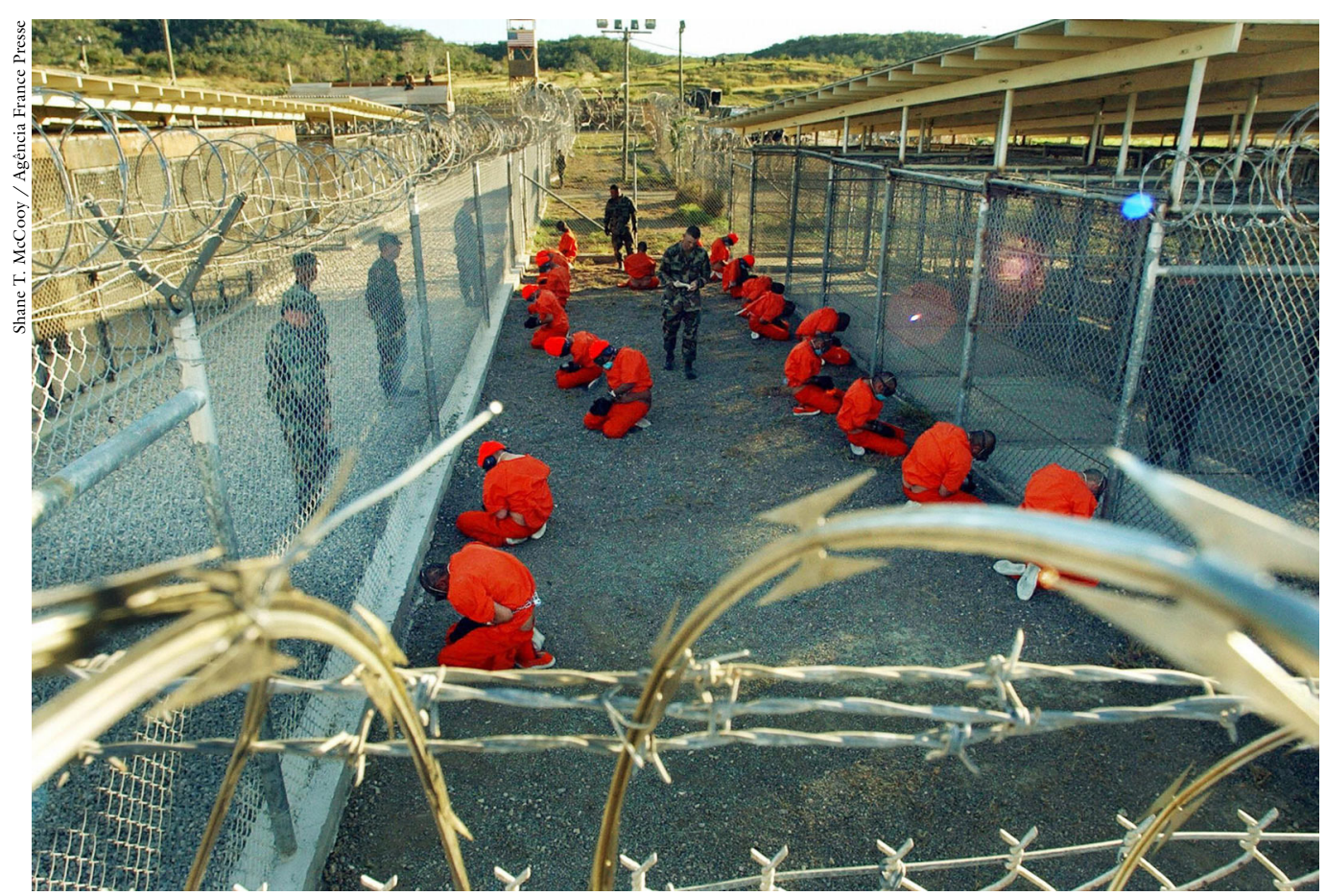

Prisioneiros da Al Qaeda e do Taliban na base naval da baía de Guantanamo, Cuba.

A assistência militar é um instrumento tradicional da política externa norte-americana. O treinamento de policiais e oficiais militares, a provisão de inteligência, planejamento e transporte, exercícios conjuntos com militares latinoamericanos, projetos cívicos e humanitários fazem parte das atividades militares 
norte-americanas na região. As atividades de contra-insurgência perderam o seu papel central após a crise Irã-Contras e o fim dos conflitos na América Central, embora tenham ocorrido as operações na Colômbia e no Peru ao longo da década de 1990.

O contato entre militares da região é estimulado por meio de um conjunto de instituições e práticas. A criação do Encontro de Ministros da Defesa das Américas intensificou as discussões estratégicas de alto nível na última década. Existem vários fóruns para as Forças Armadas da região: Conferências de Exércitos Americanos (39), Sistema de Cooperação das Forças Aéreas Americanas, Conferência Naval Inter-Americana, Simposium Internacional de Forças Marítimas, Junta de Defesa Inter-Americana, Colégio de Defesa Inter-Americana. Os programas de trocas e treinamento são um aspecto fundamental deste contato constante (40).

As bases militares são outra forma importante da extensão da presença militar norte-americana no continente. As bases no Equador (Manta), Aruba, Curaçao e El Salvador (Comalapa) fazem parte do processo de revisão de operações no pós-Guerra Fria; resultando, ainda, da retirada das forças norte-americanas do Panamá em 1999. Essas bases foram acrescentadas às de Soto Cano em Honduras, à de Guantánamo em Cuba e às de Porto Rico (41). Por outro lado, outras instalações são utilizadas pelos militares norte-americanos, como é o caso do Centro de Treinamento de Iquitos no Peru e as bases na Colômbia. Washington assinou acordos de dez anos com a Holanda, referentes a Aruba e Curaçau, com El Salvador e o Equador, e o Congresso designou \$ 116 milhões no ano fiscal de 2001 para a renovação das bases no Equador, em Aruba e Curaçau. Esses arranjos, denominados Forward Operating Locations, permitem aos militares norte-americanos, à sua guarda costeira, ao serviço de alfândega e ao DEA (Drug Enforcemet Administration), usar instalações existentes como plataformas para a luta antidrogas. O Comando Sul também opera radares no Peru (Iquitos, Andoas, Pucallpa) e na Colômbia (San José del Guaviare, Marandúa e Leticia), outros são móveis e secretos. Observa-se que a diversificação da presença militar norte-americana é uma estratégia consistente (42).

Tropas norte-americanas operam sistemas de radar, monitoram a região do ar, provêem apoio operacional e de inteligência e treinam forças de segurança locais. Desta feita constitui-se uma área de controle em terra, ar e vias aquáticas na região andina (43), em acordo com a redefinição das fontes regionais de ameaças. Embora o envio de tropas, como já mencionado, não faça parte da estratégia de intervenção no conflito colombiano, a presença militar norte-americana nos Andes é hoje muito significativa.

\section{Conclusão}

Podemos concluir que a política de segurança norte-americana após o final da Guerra Fria foi marcada por elementos de ruptura importantes que dão uma 
maior ênfase sobre os mecanismos de cooperação e concertação regionais, na incorporação da subregião andina à sua área de influência mais próxima, na diversificação da presença militar, nas novas ameaças e tentativas de redefinição do papel e da estrutura institucional das Forças Armadas na região. Por outro lado, o recurso às políticas unilaterais, a relevância dos acordos bilaterais no campo militar, a contínua assistência ao aparato militar de diferentes países, enfatizando-se o contato entre militares da região, são elementos de continuidade a serem lembrados.

Ao final da Guerra Fria, a política externa norte-americana para a América Latina parecia cumprir um ciclo marcado por uma lógica geopolítica em que o eixo da estratégia era evitar a presença de potências estrangeiras na região (44). A política de contenção da Guerra Fria era apenas a última versão de uma tendência que remonta ao século XIX. A partir dos anos 90, as ameaças à nação norteamericana advêm de fenômenos endógenos: drogas, migrações, fragilidade das instituições políticas.

Observa-se que a política de segurança norte-americana na região está impregnada de tensões. A militarização do combate ao narcotráfico atinge o processo de construção de um paradigma democrático para a região ao longo da década de 1990. Paradoxalmente, a política de combate às drogas na Colômbia tem solapado as bases institucionais de uma das mais tradicionais democracias latino-americanas. Ademais, o combate às drogas na região andina não tem favorecido o desenvolvimento de uma cultura de proteção aos direitos humanos. Da mesma forma, a tendência do atual governo, congruente com sua perspectiva de ordem hegemônica de concentrar-se em medidas unilaterais e relações bilaterais abala os alicerces das instituições multilaterais geradas durante a última década.

A dificuldade que as lideranças norte-americanas têm de incorporar os conflitos interestatais à sua perspectiva do sistema de segurança regional leva os Estados Unidos ao despreparo diante de conflitos territoriais como entre a Argentina e a Grã-Bretanha, entre o Chile e a Argentina, o Peru e o Equador, a Colômbia e a Venezuela, dentre outros (45). As medidas de segurança mútua, incentivadas pelo governo norte-americano, não resolvem os conflitos originais entre as partes, embora possam gerar um ambiente mais propício que assegura um bom resultado das negociações. Além disso, o Estado é a unidade de análise para a criação de medidas de confiança em um contexto onde a maior parte das ameaças advém de atores não-estatais (46).

As tensões entre a agenda econômica e a de segurança são bastante evidentes. Buscou-se concomitantemente pressionar os governos do hemisfério para que reformas econômicas fossem implementadas, de acordo com as receitas do FMI, e para que o cumprimento de legislações criminais fosse garantido. As nações da região são colocadas sob a égide de uma tensão inerente entre uma proposta de Estado minimalista nas suas relações com o mercado e do aumento do papel do Estado no combate à criminalidade (47). Por outro lado, a decisão de 
liberar a venda de equipamento militar avançado para a região, respondendo a interesses econômicos domésticos, não favorece a busca de estabilidade, mas pode gerar uma minicorrida armamentista, representando custos elevados para sociedades enfrentando crises econômicas e sociais profundas.

Diante do maior desafio à estabilidade na região - o conflito colombiano -, o governo dos EUA tem recorrido a uma postura unilateralista, limitando-se a lidar com o Estado colombiano na esfera bilateral. A liderança norte-americana não tem se mostrado disposta a arcar com os custos de um processo de concertação multilateral no âmbito das instituições criadas ou reformadas ao longo dos anos de 1990. Este é o mais importante indicador da direção tomada pela potência hegemônica em face da necessidade de garantir e fortalecer as instituições multilaterais regionais.

\section{Notas}

1 Lars Schoultz, William C. Simth, "Introduction" in Lars Schoultz, William \& Augusto Varas. C. Smith \& Augusto Varas, Security, democracy, and development in U.S.-Latin American relations. Miami, North-South Center Press, 1994.

2 Para uma discussão sobre a invasão do Panamá, em que a luta contra o narcotráfico, a necessidade de afirmar a liderança dos Estados Unidos no contexto do final da Guerra Fria e a agenda de defesa da democracia no continente são enfatizados, ver Eytan Gilboa, "The Panama Invasion Revisited: Lessons for the Use of Force in the Post-Cold War Era", in Demetrios James Caraley (ed.), The new american interventionism, Columbia University Press, 1999,

3 Por exemplo, Abraham Lowenthal, "Latin America: Ready for Partnership?". Foreign Affairs 72, n.1, p.74-92. Michael C. Desch, "Why Latin America May Miss the Cold War", in Jorge Domínguez, International security \& democracy, Pittsburgh, Pittsburgh Press, 1998.

4 Por exemplo, Ronnie D. Lipschutz (ed.) (1995), On Security, Nova York, Columbia University Press. J. Ann Tickner (1995), "Re-visioning Security", in Ken Booth \& Steve Smith, International relations theory today, Oxford, Polity Press. Barry Buzan (1991), People, states and fear: an agenda for international security studies in the post Cold War Era, Londres, Harvester Wheatsheaf. Jessica Mathews (1991), "The Environment and International Security", in Klare \& Thomas (1991), World security:trends and challenges at century's end, Nova York, St Martin's Press. David Baldwin (1997), "The Concept of Security", Review of international studies, n.23.

5 The White House, A national security strategy for a new century, dez. 1999 (acesso em 14 de agosto de 2002) http://usinfo.state.gov/regional/ar/natsec $2 \mathrm{k}$ ).

6 Em 1991, Brasil, Argentina e Chile assinaram a Declaração de Mendoza se comprometendo a não produzir, comprar, armazenar, usar ou transferir armas químicas ou biológicas. Bolívia, Equador, Paraguai e Uruguai também aderiram à Declaração. A Declaração de Cartagena, assinada em dezembro de 1991, compromete os países andinos à renunciar as armas de destruição em massa. Em fevereiro 
de 1995, a Argentina aderiu ao Tratado de Não-Proliferação Nuclear e, em 1998, o Brasil fez o mesmo.

7 Gabriel Marcella, “The U. S. Engagement with Colombia: Legitimate State Authority and Human Rights", The North-South Agenda, n. 55, mar. 2002.

8 Jorge Dominguez, “The Future of Inter-American Relations”, Working Paper, Inter-American Dialogue, 1999, p.3.

9 O comitê foi criado em 1986 e teve um plano de ação aprovado pela Assembléia Geral da OEA em 1990 (AG/RES.1045). Mecanismos de avaliação e regulação do tráfico de drogas e atividades conexas foram criados ao longo década.

10 Inter-American Defense Board, Toward a New Hemispheric Security System, 6 set. 2001.

11 Monica Herz e João Pontes Nogueira, Ecuador vs. Peru, peacemaking amid rivalry, Bolder, Lynne Rienner, 2002.

12 Ashton B. Carter, William Perry e John Steinbruner (1992), A new concept of cooperative security, Washington, C. C., Brookings Institution. O diplomata argentino Hernán Patiño Meyer foi um dos defensores desta perspectiva na América Latina. Ver Conselho Permanente da OEA, Comitê de Segurança Hemisférica, "Support for a New Concept of Hemisphere Security", OEA/Ser.G, CE/SH12/93, 17 maio 1993.

13 A assistência para o treinamento para operações de paz é feito por um programa específico - Enhanced International Peacekeeping Capabilities Initiative - do qual participaram, segundo dados de 2000, Argentina, Bolívia, Chile e Uruguai. Congressinal Presentation for Foreign Operations, Washington, mar. 2000 (acesso em 14 ago. 2002) www.state.gov/www/budget/fy2001/fn l50/forops.

14 Esta visão está clara no documento "Quadrennial Defense Review Report", 30 set. 2001, Departamento de Defesa dos EUA.

15 Ver President's National Security Strategy-ago. 1991, jan. 1993; National Military Strategy - jan. 1992.

16 Nina Serafino, "U.S. Military Activities in Latin America: U.S. Government Rationales and Perceptions" in Lars Schoultz, William C. Simth \& Augusto Varas, Security, democracy, and development in U.S.-Latin American relations, Miami, North-South Center Press, 1994,.

17 Augusto Varas, "Post-Cold War Security Interests and Perceptions of Threat in the Western Hemisphere", in Lars Schoultz, William C. Simth \& Augusto Varas, Security, democracy, and development in U.s.-Latin American relations, Miami, North-soth Center Press, 1994, p.3.

18 As disputas entre a Colômbia e a Venezuela quanto à delimitação do golfo da Venezuela, o conflito entre a Colômbia e a Nicarágua sobre as ilhas San Andrés, a disputa entre a Venezuela e a Guiana quanto à região de Esequibo são alguns exemplos.

19 Augusto Varas, "Post-Cold War Security Interests and Perceptions of Threat in the Western Hemisphere", in Lars Schoultz, William C. Simth \& Augusto Varas, Security, democracy, and development in U.S.-Latin American relations, Miami, North-South Center Press, 1994. 
20 Ver Thomas S. Bodenheimer \& Robert Gould, "U.S. Military Doctrine and their Relations to Foregin Policy", in Augusto Varas, Hemispheric security and U.S. policy in Latin America, boulder, Colorado, Westview Press, 1989.

21 Em 1977, o presidente Jimmy Carter reverteu a Doutrina Nixon que favorecia a transferência de armas como mecanismo de contenção do bloco soviético. A partir de então a venda de armas para a América Latina foi limitada em decorrência do desrespeito aos direitos humanos na região e do principio de não introduzir armas com grau de sofisticação mais elevado em uma determinada região. Frank Mora \& Antonio Pala, "US Arms Transfer Policy for Latin America", Airpower Journal, 1999, p. 2.

22 Michael Klare, "The Perspectives of the U.S. Government and Private Military Suppliers", in Lars Schoultz, William C. Simth \& Augusto Varas, Security, democracy, and development in U.S.-Latin American relations, Miami, NorthSouth Center Press, 1994, p.161.

23 "Changes in the Law Governing U.S. Security Assistance to Latin America and the Caribbean", in 2001 (acesso em 17 ago. 2002) www.ciponline.org/facts/ legis01.htm.

24 Rodolfo Cerdas Cruz, "United States Foreign Relations and the Promotion of Democracy in Latin America", in Victor Bulmer-Thomas e James Dunkerley, The United States and Latin America: the New Agenda, Londres, Institute of Latin American Studies, 1999.

25 The White House, A National Security Strategy for a New Century, dez. 1999 (acesso em 14 ago. 2002) http://usinfo.state.gov/regional/ar/natsec2k), p. 48.

26 Lars Schoultz, "U.S. Values and Approaches to Hemispheric Security Issues", in Lars Schoultz, William C. Simth \& Augusto Varas, Security, democracy, and development in U.S.-Latin American relations, Miami, North-South Center Press, 1994, p. 46.

27Citado em Nina Serafino, "U.S. Military Activities in Latin America: U.S. Government Rationales and Perceptions", in Lars Schoultz, William C. Simth \& Augusto Varas, Security, democracy, and development in U.S.-Latin American relations, Miami, North-South Center Press, 1994, p. 62.

28 Gina Amatangelo, "Militarization of the U.S. Drug Control Program”, Foreign Policy In Focus, v.6, n.17, maio 2001.

29 Adam Isacson e Joy Olson, "Just the Facts: a quick Tour of U.S. Defense and Security Assistance to Latin America and the Caribbean", International Policy Report, dez., 1998, p. 4-5.

30 Gina Amatangelo, "Militarization of the U.S. Drug Control Program”, Foreign Policy In Focus, v.6, n.17, maio 2001, p.4.

31 Center For International Policy, "U.S. Security Assitance to the Andean Region", 2000-2001 (acesso em 25 ago. 2002) www.ciponline.org.

32 M Weiner, "Security, Stability and International Migration", International Security, v.17, n.3, 1992.

33"Mass Migration from Haiti and Cuba: Lessons Learned", Refugee and 
Humanitarian Admissions, U.S. Commission on Immigration Reform, 5 dez.1994.

34Kenneth J. Franzblau, "U.S. Immigration and Foreign Policy", in U. S. Commission on Immigration Reform, Refugee and Humanitarian Admissions, Research Paper 1, 1997, p. 428-52.

35 Jorge I. Domínguez, "U.S.-Latin American Relations during the Cold War and its Aftermath", Working Paper Sereis 99-101, Weatherhead Center for International Affairs, Harvard University, 1999, p. 12.

36 Adam Isacson, "Militarizing Latin American Policy", Foreign Policy in Focus, v. 6 n.21, 2001.

37 Center for International Policy, U.S. Southern Command (acesso em 15 ago. 2002) www.ciponline.org/facts/dodsc.l.

38 Para esta discussão ver J. Samuel Fitch, "The Decline of U. S. Military Influence in Latin America", in Lars Schoultz, William C. Simth \& Augusto Varas, Security, democracy, and development in U.S.-Latin American relations, Miami, NorthSouth Center Press, 1994.

39 Os comandantes em chefe dos Exércitos Americanos encontram-se neste fórum.

40 Os dois principais centros de treinamento nos Estados Unidos são o Instituto para a Cooperação em Segurança do Hemisfério Ocidental (antes a Escola das Américas) em Fort Benning, Georgia, e Academia Inter-Americana das Forças Aéreas na base aérea de Lackland, no Texas. Militares da região participam de diversos programas para militares e policiais como o Programa Internacional para Educação e Treinamento Militar dos EUA (IMET). Em 1998, por exemplo, quase 10 mil militares latino-americanos receberam treinamento de instituições norte-americanas e 48.132 militares norte-americanos estiveram na América Latina e no Caribe. Ver “Just the Facts: a Civilian's Guide to U.S. Defense and Security Assistance to Latin America and the Caribbean", Latin America Working Group (acesso em 18 ago. 2002) www.ciponline.org, p.11.

41 Em 1997, Vieques é incorporada ao Comando Sul; antes a base fazia parte do Comando Atlântico.

42 John Lindsay-Poland, "U.S. Military Bases in Latin America and the Caribbean”, Foreign Policy in Focus, v. 6, n. 35, 2001, p.1. Center For International Policy, Counter-Drug Radar Sites (acesso em 18 ago. 2002) http://ciponline.org/facts/ radar.htm.

43 Michael L. Evans, "U.S. Drug Policy \& Intelligence Operations in the Andes", Foreign Policy in Focus, v. 6 , n. 22, 2001, p.1-2.

44Para uma discussão sobre esta tradição, ver Lars Schoultz, "U.S. Values and Approaches to Hemispheric Security Issues", in Lars Schoultz, William C. Simth \& Augusto Varas, Security, democracy, and development in U.S.-Latin American relations, Miami, North-South Center Press, 1994.

45 Este é o argumento de Paul G. Buchanan, "Chameleon, Tortoise, or Toad", in Jorge Domínguez, International Security \& Democracy, Pittsburgh, Pittsburgh Press, 1998. 
46 Paul Buchanan salienta as contradições inerentes ao translado de conceitos elaborados no contexto das relações transatlânicas para o hemisfério ocidental. Paul Buchanan, op. cit., p. 282-83.

47 Peter Andreas, "Free Market Reform and Drug Market Prohibition: US Policies at Cross-Purposes in Latin America", Third World Quarterly, v.16, n.1, 1995.

RESUMO - O ARTIGO analisa a política de segurança dos EUA para a América Latina a partir do final da Guerra Fria. São consideradas as principais transformações deste aspecto da política externa norte americana para a região. A tendência à incorporação de novos temas à agenda de segurança, em particular a manutenção de regimes democrático, $\mathrm{o}$ narcotráfego e as migrações é investigada, assim como a presença militar norte americana na região. A relevância que a região andina adquire nos anos 90 e a disposição das três primeiras administrações do pós Guerra Fria de incentivar mecanismos multilaterais para a área da segurança também são avaliados.

ABSTRACT - THE ARTICLE analyses North American security policy regarding Latin America since the end of the Cold War. The main transformations of this aspect of the US's foreign policy toward the region are considered. The tendency to incorporate new themes to the security agenda, such as the preservation of democracy, drug traffic and production and illegal migration is investigated. The US military presence in the region is also looked into. The importance that the Andean sub region acquired during the 1990s and the desire of the three first post Cold War administrations to stimulate the creation and reconstruction of multilateral mechanisms in the security sphere are evaluated.

Monica Herz é professora do Instituto de Relações Internacionais da Pontifícia Universidade Católica do Rio de Janeiro (PUC-RJ). É Phd em Relações Internacionais (London School of Economics). 